\title{
Erratum to: Divergent Responses of Soil Fungi Functional Groups to Short-term Warming
}

\author{
Jinbo Xiong • Fei Peng $\cdot$ Huaibo Sun $\cdot$ Huayong Zhang • \\ Xian Xue $\cdot$ Haiyan Chu
}

Published online: 30 July 2014

(C) Springer Science+Business Media New York 2014

\section{Erratum to: Microb Ecol \\ DOI 10.1007/s00248-014-0385-6}

The authorship was not correct and the affiliations incomplete. Haiyan $\mathrm{Chu}(\mathrm{HC}$ ) should be identified as a senior author and cocorresponding author. As the work was done in the Institute of Soil Science, Chinese Academy of Sciences, the first affiliation of this manuscript and Jinbo Xiong's (JX) primary affiliation should be the Institute of Soil Science, Chinese Academy of Sciences. Huayong Zhang (HZ) has been added as a co-author. The roles of each author are identified as follows:

Author Contributions:

HC, JX and XX originally formulated the idea $\mathrm{JX}$ and $\mathrm{HC}$ developed methodology FP, HS and XX conducted fieldwork FP and HS did soil biogeochemical analyses and molecular analyses

$\mathrm{HZ}$ and $\mathrm{HC}$ generated sequencing data

JX, HZ, HC performed data analyses

JX wrote the manuscript

The online version of the original article can be found at http://dx.doi.org/ 10.1007/s00248-014-0385-6.

J. Xiong $(\bowtie) \cdot H$. Sun $\cdot$ H. Zhang $\cdot$ H. Chu

State Key Laboratory of Soil and Sustainable Agriculture, Institute of

Soil Science, Chinese Academy of Sciences, Nanjing, China

e-mail: xiongjinbo@nbu.edu.cn

H. Chu

e-mail: hychu@issas.ac.cn

F. Peng $\cdot X$. Xue

Key Laboratory of Desert and Desertification, Cold and Arid

Regions Environmental and Engineering Research Institute, Chinese

Academy of Sciences, Lanzhou, China

J. Xiong

Faculty of Marine Sciences, Ningbo University, Ningbo, China 